\title{
Prognostic significance of the pretreatment serum gamma- glutamyltransferase levels in Chinese patients with non-metastatic cervical cancer
}

\author{
Yi Zhu ${ }^{1}$, Ai-Jun Zhang ${ }^{1}$, Da-Bao Wu ${ }^{1}$, Zhen Shen ${ }^{1}$, Gang Chen ${ }^{1}$, Yang-Yang Shi $^{1}$, \\ Hao $\mathrm{Wu}^{1}$ and Jing Wang ${ }^{1}$ \\ ${ }^{1}$ Department of Obstetrics and Gynecology, Anhui Provincial Hospital Affiliated Anhui Medical University, Hefei, Anhui, \\ 230001, People's Republic of China
}

Correspondence to: Jing Wang, email: wang19620909@126.com

Keywords: cervical cancer, serum gamma-glutamyltransferase, GGT, survival

Received: January 09, $2017 \quad$ Accepted: September 18, $2017 \quad$ Published: November 01, 2017

Copyright: Zhu et al. This is an open-access article distributed under the terms of the Creative Commons Attribution License 3.0 (CC BY 3.0), which permits unrestricted use, distribution, and reproduction in any medium, provided the original author and source are credited.

\section{ABSTRACT}

This study was performed to evaluate the prognostic significance of the pretreatment serum gamma-glutamyltransferase (GGT) levels in a Chinese cohort of patients with early-stage or locally advanced cervical cancer. The pretreatment serum GGT levels were examined in 290 cervical cancer patients with stage I-III disease and $\mathbf{2 3 0}$ healthy controls selected from a cancer-free population in the same region. Patients were assigned to normal or high-risk GGT groups, as previously described, and the GGT levels were correlated to clinicopathologic parameters and survival data. The GGT levels in cervical cancer patients were significantly higher than those in healthy controls (35.6 \pm 29.1 vs. $24.1 \pm 14.7 \mathrm{U} / \mathrm{L}, P<0.001)$. In addition, the pretreatment serum GGT levels were associated with the histology type $(P=0.023)$, lymph node involvement $(P=0.040)$, stage $(P=0.029)$, recurrence $(P=0.015)$ and death $(P=0.005)$, but not with age $(P=0.432)$, tumor size $(P=0.067)$ or degree of differentiation $(P=\mathbf{0 . 9 0 1})$. Moreover, univariate survival analysis revealed that patients with high GGT levels tended to have poorer disease-free survival (DFS) [hazard ratio (HR), 1.721; 95\% confidence interval (CI), 1.189-2.491; $P=0.004$ ] and overall survival (OS) $(H R, 1.929 ; 95 \% C I, 1.294-2.876 ; P=0.001)$ compared to those with normal GGT levels. However, a multivariate Cox-regression model did not support these data (HR, 1.373; 95\% CI, 0.925-2.039; $P=0.116$ for DFS and $H R, 1.357 ; 95 \% C I, 0.887-2.078 ; P=0.160$ for $O S$, respectively) after adjusting for other confounding variables. High pretreatment serum GGT was associated with more advanced tumor behavior, but could not serve as an independent prognostic indicator in patients with early-stage or locally advanced cervical cancer.

\section{INTRODUCTION}

Cervical cancer is one of the most commonly diagnosed cancers and is high in incidence and mortality among women worldwide. The morbidity and mortality in developed countries have decreased dramatically as a result of thorough screening with Papanicolaou tests, early treatment of preinvasive lesions, as well as vaccination against human papillomavirus (HPV) [1-5]. However, in many developing regions, cervical cancer remains a major cause of death in women, with approximately 530,000 new cases and 275,000 deaths annually [2]. Although earlystage and locally advanced cervical cancer can be cured with radical surgery, chemoradiotherapy, or a combination of these treatments, patients with metastatic or recurrent disease following platinum-based chemoradiotherapy have limited options [6-7], and the prognosis remains poor. Several markers have recently been proposed as potential prognostic factors, including squamous cell carcinoma antigen, cancer antigen-125 and plasma fibrinogen [8]. 
However, there is still a lack of an optimal indicator to estimate the recurrence risk and outcome in patients with early-stage or locally advanced cervical cancer.

Gamma-glutamyltransferase (GGT) is a membranebound enzyme that is involved in glutathione (GSH) metabolism by transferring gamma-glutamyl functional groups. GSH has been identified as a major water-soluble antioxidant in cells and protects cells against oxidants by neutralizing reactive oxygen compounds and free radicals that are produced during normal metabolism [9-10]. Thus, an increase in GGT and GSH levels is frequently observed in pathological states of oxidative stress [10-11]. Moreover, in addition to serving as a routine marker for hepatobiliary disease [9, 12], GGT can also modulate the cellular proliferative and apoptotic balance and plays an important role in cancer development, progression, invasion, and anticancer drug resistance [13-16]. Recently, GGT has gained increased attention as an independent prognostic biomarker in various malignancies, including renal cell carcinoma, ovarian cancer, endometrial cancer, as well as esophageal squamous cell carcinoma [17-19]. Very recently, high pre-therapeutic GGT levels have been identified to be associated with advanced tumor stages, but did not predict survival in patients with cervical cancer [20].

Therefore, the aim of the present study was to investigate the potential prognostic significance of the pretreatment serum GGT levels in a large Chinese cohort of patients with early-stage or locally advanced cervical cancer.

\section{RESULTS}

\section{Serum GGT levels in cervical cancer patients and healthy controls}

A consecutive cohort of 290 patient with stage I-III cervical cancer and 230 healthy controls were enrolled in the study. The median age was 45 (range, 20-81 years) for cancer patients and 46 (range, 21-80) for control subjects. No statistically significant differences in age, gender and comorbidities were found between the patients and the healthy subjects. The serum GGT levels were significantly higher in cervical cancer patients than those of healthy controls $(35.6 \pm 29.1$ vs. $24.1 \pm 14.7 \mathrm{U} / \mathrm{L}, P<0.001$, Figure 1). Moreover, high-risk GGT levels were more frequently seen in cervical cancer patients compared to the control subjects ( $36.2 \%$ vs $14.3 \%)$.

\section{Patient demographics}

Of the 290 included patients, $272(93.8 \%)$ patients had squamous cell carcinoma, while $18(6.2 \%)$ had nonsquamous cell carcinoma. A total of $145(50.0 \%)$ patients were classified as stage I, $101(34.8 \%)$ as stage II and $44(15.2 \%)$ as stage III. The number of patients with poorly, moderately and well-differentiated tumors was
$65(22.4 \%), 181(62.4 \%)$ and $44(15.2 \%)$, respectively. The clinicopathologic parameters of the 290 patients are presented in Table 1.

\section{Association between serum GGT levels and clinicopathologic parameters}

The relationship between serum GGT levels and clinicopathologic features is summarized in Table 1. The results indicated that a high-risk GGT group affiliation was significantly associated with the histology type $(P=0.023)$, lymph node involvement $(P=0.040)$, FIGO stage $(P=0.029)$, recurrence $(P=0.015)$ and death $(P=0.005)$ but not with patients' age $(P=0.432)$, tumor size $(P=0.067)$ or degree of differentiation $(P=0.901)$.

\section{Prognostic significance of the pretreatment serum GGT levels}

Univariate survival analysis of DFS demonstrated that the high-risk GGT group was significantly more likely to experience reduced DFS (HR, 1.721; 95\% CI, $1.189-2.491 ; P=0.004$; Figure 2) than those with normal serum GGT levels. Tumor size $(<4 / \geq 4 \mathrm{~cm})$, lymph node involvement (Negative/Positive) and tumor stage (I/ II/III) also constituted significant prognostic variables, as identified by univariate analysis $(P<0.05$, Table 2$)$. Moreover, Kaplan-Meier survival analysis of OS indicated that patients with high-risk GGT levels tended to have lower OS rates (HR, 1.929; 95\% CI, 1.294-2.876; $P=$ 0.001 ; Figure 3 ). In addition, other parameters, including tumor size, lymph node involvement and tumor stage was also significantly predictive of OS in cervical cancer patients (Table 3). However, the multivariate Coxregression model analysis of DFS and OS failed to identify baseline serum GGT levels as an independent prognostic indicator (HR, 1.373; 95\% CI, 0.925-2.039; $P=0.116$ for DFS and HR, 1.357; 95\% CI, 0.887-2.078; $P=0.160$ for OS, respectively, Tables 2 and 3) after adjusting for other confounding variables. As expected, tumor size, lymph node involvement and tumor stage were identified as significant prognostic variables for both DFS and OS.

\section{DISCUSSION}

A possible relationship between serum GGT and the incidence, as well as the prognosis, of various malignancies such as hepatocellular carcinoma, esophageal squamous cell carcinoma and many gynecological tumors has gained increased attention [17-20]. Recently, Strasak et al. reported a statistically significant association between GGT and invasive cervical cancer risk. In addition, they identified GGT as a prognostic marker for cervical cancer, suggesting that increased levels of serum GGT were associated with an increased risk of the progression of premalignant cervical lesions to invasive cancer [21]. 
Table 1: The association of the pretreatment serum GGT levels with clinicopathologic characteristics in 290 non-metastatic cervical cancer patients

\begin{tabular}{|c|c|c|c|c|}
\hline \multirow{2}{*}{$\begin{array}{l}\text { Clinicopathologic } \\
\text { characteristics }\end{array}$} & \multirow{2}{*}{$\begin{array}{l}\text { Patients } \\
N(\%)\end{array}$} & \multicolumn{2}{|c|}{ Serum GGT level $(N, \%)$} & \multirow{2}{*}{$P$ value } \\
\hline & & Normal $(<36.0 \mathrm{U} / \mathrm{L})$ & High $(\geq 36.0 \mathrm{U} / \mathrm{L})$ & \\
\hline Age (years) & & & & 0.432 \\
\hline$<45$ & $122(42.1)$ & $81(43.8)$ & $41(39.0)$ & \\
\hline$\geq 45$ & $168(57.9)$ & $104(56.2)$ & $64(61.0)$ & \\
\hline Tumor size $(\mathrm{cm})$ & & & & 0.067 \\
\hline$<4$ & $145(50.0)$ & $100(54.1)$ & $45(42.9)$ & \\
\hline$\geq 4$ & $145(50.0)$ & $85(45.9)$ & $60(57.1)$ & \\
\hline Histology type & & & & $0.023^{*}$ \\
\hline SCC & $272(93.8)$ & $178(96.2)$ & $94(89.5)$ & \\
\hline Non-SCC & $18(6.2)$ & $7(3.8)$ & $11(10.5)$ & \\
\hline Degree of Differentiation & & & & 0.901 \\
\hline G1 & $44(15.2)$ & $28(15.1)$ & $16(15.2)$ & \\
\hline $\mathrm{G} 2$ & $181(62.4)$ & $114(61.6)$ & $67(63.8)$ & \\
\hline G3 & $65(22.4)$ & $43(23.2)$ & $22(21.0)$ & \\
\hline Lymph node involvement & & & & $0.040^{*}$ \\
\hline Negative & $180(62.1)$ & $123(66.5)$ & $57(54.3)$ & \\
\hline Positive & $110(37.9)$ & $62(33.5)$ & $48(45.7)$ & \\
\hline FIGO Stage & & & & $0.029^{*}$ \\
\hline I & $145(50.0)$ & $103(55.7)$ & $42(40.0)$ & \\
\hline II & $101(34.8)$ & $59(31.9)$ & $42(40.0)$ & \\
\hline III & $44(15.2)$ & $23(12.4)$ & $21(20.0)$ & \\
\hline Recurrence & & & & $0.015^{*}$ \\
\hline No & $176(60.7)$ & $122(65.9)$ & $54(51.4)$ & \\
\hline Yes & $114(39.3)$ & $63(34.1)$ & $51(48.6)$ & \\
\hline Death & & & & $0.005^{*}$ \\
\hline No & $193(66.6)$ & $134(72.4)$ & $59(56.2)$ & \\
\hline Yes & $97(33.4)$ & $51(27.6)$ & $46(43.8)$ & \\
\hline
\end{tabular}

GGT, gamma-glutamyltransferase; SCC, squamous cell carcinoma; FIGO, international federation of gynecology and obstetrics.

${ }^{*} P<0.05$.

Table 2: Univariate and multivariate analysis of DFS in 290 cervical cancer patients

\begin{tabular}{|c|c|c|c|c|c|c|}
\hline \multirow{2}{*}{ Variables } & \multicolumn{3}{|c|}{ Univariate } & \multicolumn{3}{|c|}{ Multivariate } \\
\hline & HR & $95 \% \mathrm{CI}$ & $\boldsymbol{P}$ & HR & $95 \% \mathrm{CI}$ & $\boldsymbol{P}$ \\
\hline Age $(<45$ vs. $\geq 45$ years $)$ & 1.286 & $0.874-2.156$ & 0.283 & 1.246 & $0.818-1.194$ & 0.267 \\
\hline Tumor size $(\geq 4.0$ vs. $<4.0 \mathrm{~cm})$ & 3.687 & $2.442-5.566$ & $<0.001^{*}$ & 2.444 & $1.599-3.737$ & $<0.001^{*}$ \\
\hline Histology type (SCC vs. Non-SCC) & 1.474 & $0.746-2.911$ & 0.264 & 1.401 & $0.683-2.876$ & 0.358 \\
\hline Degree of differentiation (G1 vs. G2 vs. G3) & 0.862 & $0.640-1.160$ & 0.326 & 0.841 & $0.596-1.186$ & 0.323 \\
\hline Lymph node involvement (Positive vs. Negative) & 2.418 & $1.672-3.496$ & $<0.001^{*}$ & 1.579 & $1.080-2.308$ & $0.019^{*}$ \\
\hline Tumor stage (FIGO III vs. II vs. I) & 4.116 & $3.686-6.982$ & $<0.001^{*}$ & 4.029 & $2.492-6.093$ & $<0.001^{*}$ \\
\hline GGT groups (High vs. Normal) & 1.721 & $1.189-2.491$ & $0.004^{*}$ & 1.373 & $0.925-2.039$ & 0.116 \\
\hline
\end{tabular}

DFS, disease-free survival; HR, hazard ratio; CI, confidence interval.

${ }^{*} P<0.05$. 
Table 3: Univariate and multivariate analysis of OS in 290 cervical cancer patients

\begin{tabular}{|c|c|c|c|c|c|c|}
\hline \multirow{2}{*}{ Variables } & \multicolumn{3}{|c|}{ Univariate } & \multicolumn{3}{|c|}{ Multivariate } \\
\hline & HR & $95 \% \mathrm{CI}$ & $\boldsymbol{P}$ & HR & $95 \% \mathrm{CI}$ & $\boldsymbol{P}$ \\
\hline Age $(<45$ vs. $\geq 45$ years $)$ & 1.387 & $0.796-1.983$ & 0.346 & 1.046 & $0.683-1.342$ & 0.423 \\
\hline Tumor size $(\geq 4.0$ vs. $<4.0 \mathrm{~cm})$ & 4.356 & $2.766-5.584$ & $<0.001^{*}$ & 3.298 & $1.986-4.877$ & $<0.001^{*}$ \\
\hline Histology type (SCC vs. Non-SCC) & 1.701 & $0.857-3.379$ & 0.264 & 1.321 & $0.637-2.740$ & 0.455 \\
\hline Degree of differentiation (G1 vs. G2 vs. G3) & 0.935 & $0.674-1.299$ & 0.690 & 1.046 & $0.724-1.513$ & 0.810 \\
\hline Lymph node involvement (Positive vs. Negative) & 2.707 & $1.810-4.049$ & $<0.001^{*}$ & 1.591 & $1.045-2.423$ & $0.030^{*}$ \\
\hline Tumor stage (FIGO III vs. II vs. I) & 4.491 & $3.129-6.316$ & $<0.001^{*}$ & 3.618 & $2.531-4.912$ & $<0.001^{*}$ \\
\hline GGT groups (High vs. Normal) & 1.929 & $1.294-2.876$ & $0.001^{*}$ & 1.357 & $0.887-2.078$ & 0.160 \\
\hline
\end{tabular}

OS, overall survival.

${ }^{*} P<0.05$.

However, published data on the potential prognostic impact of serum GGT are very limited.

In a recent retrospective analysis, Polterauer et al. assigned 692 patients with cervical cancer to previously described GGT risk groups and performed uni- and multivariate survival analysis. They determined that the GGT serum levels were associated with FIGO stage and age but not with lymph node involvement or histology type. Moreover, a high-risk GGT group affiliation was significantly associated with poor DFS and OS in a univariate analysis. However, this finding was not confirmed in a multivariate survival analysis, likely due to the strong association between tumor stage and GGT [20]. Therefore, they suggested that GGT may serve as a marker of disease progression, rather than as an independent prognostic indicator. Nevertheless, in accordance with their findings, the results from the present analysis of 290 patients with early-stage or locally advanced cervical cancer revealed that subjects with an elevated $(\geq 36.0 \mathrm{U} / \mathrm{L})$ serum GGT level prior to treatment had substantially shorter DFS and OS as indicated by the univariate analysis. Unfortunately, we failed to demonstrate the baseline serum GTT level as an independent prognostic variable in this group of patients. Moreover, the preoperative serum GGT levels did not represent an independent prognostic factor in a European cohort of patients with non-metastatic renal cell carcinoma [22].

Serum GGT is routinely used as a sensitive indicator of hepatobiliary disorder and a marker of alcohol intake in clinical practice $[9,12]$. In addition, its ability to regulate

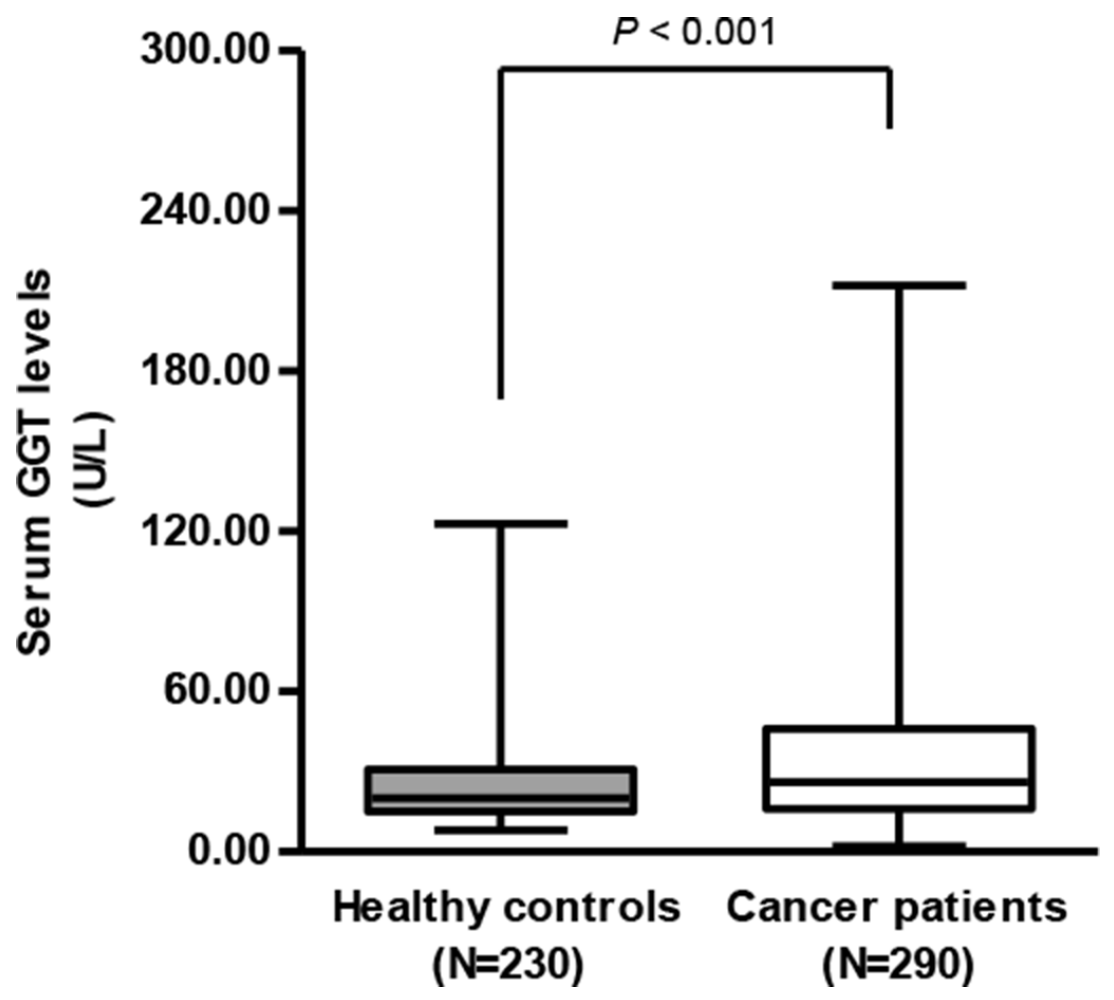

Figure 1: Serum GGT levels in cervical cancer patients $(N=290)$ was significantly higher than those of healthy controls $(N=230)(35.6 \pm 29.1$ vs. $24.1 \pm 14.7 \mathrm{U} / \mathrm{L}$, student's $t$-test, $P<0.001)$. 
redox-sensitive functions, including cellular proliferation and apoptotic balance, as well as antioxidant effects has been confirmed. Moreover, it has also been suggested to play a role in tumor progression, invasion, and drug resistance [13-16]. However, the specific mechanisms by which GGT becomes elevated in cancer patients remains poorly understood. As previously described, GSH is crucial in the removal and detoxification of various carcinogens by conjugating with them in the extracellular microenvironment [9-11, 23]. As cellular GGT is indispensable for the metabolism of extracellular GSH conjugates, higher serum GGT levels reflect more xenobiotics that require conjugation and the corresponding increased cellular GGT activity to metabolize them [21]. Thus, the elevation of GGT may be an indicator in the development of an aggressive disease [20]. Moreover, researchers have demonstrated that serum GGT elevation may act as a part of the activation of the host immune response as a mechanism of immune-mediated cancer rejection. Meanwhile, the tumor itself may also produce GGT, leading to increased circulating GGT levels in the serum $[11,16]$. Further research is warranted in order to elucidate the exact biological mechanisms linking serum GGT levels to advanced tumor behavior.

As with all retrospective studies, the main limitations of this study were the retrospective design, the long study period and the multiple surgeons involved. Despite these limitations, our study demonstrated that high serum GGT levels prior to treatment were associated with advanced tumor behavior but could not serve as an independent prognostic factor in patients with early-stage or locally advanced cervical cancer. Large-scale prospective studies are needed before baseline serum GGT levels can be introduced as a routine marker in specific patients.

\section{MATERIALS AND METHODS}

\section{Patients}

A total of 290 patients with early-stage or locally advanced cervical cancer who were treated in the Department of Obstetrics and Gynecology at the Anhui Provincial Hospital Affiliated Anhui Medical University (Hefei, China) between January 2005 and December 2010 were included in this study. Patients with malignant disease other than cervical cancer and those presenting with pre-existing comorbidities or medications related to elevated GGT (i.e., hepatobiliary tract, pancreatic, and heart disease or alcohol abuse) were excluded from the study. Healthy controls were selected from a cancer- and hepatobiliary disease-free population in the same region for comparison of GGT levels (Figure 4).

Briefly, subjects with microinvasive disease were treated with conization or hysterectomy combined with systematic pelvic/periaortic lymphadenectomy. Radical hysterectomy or trachelectomy with systematic pelvic/

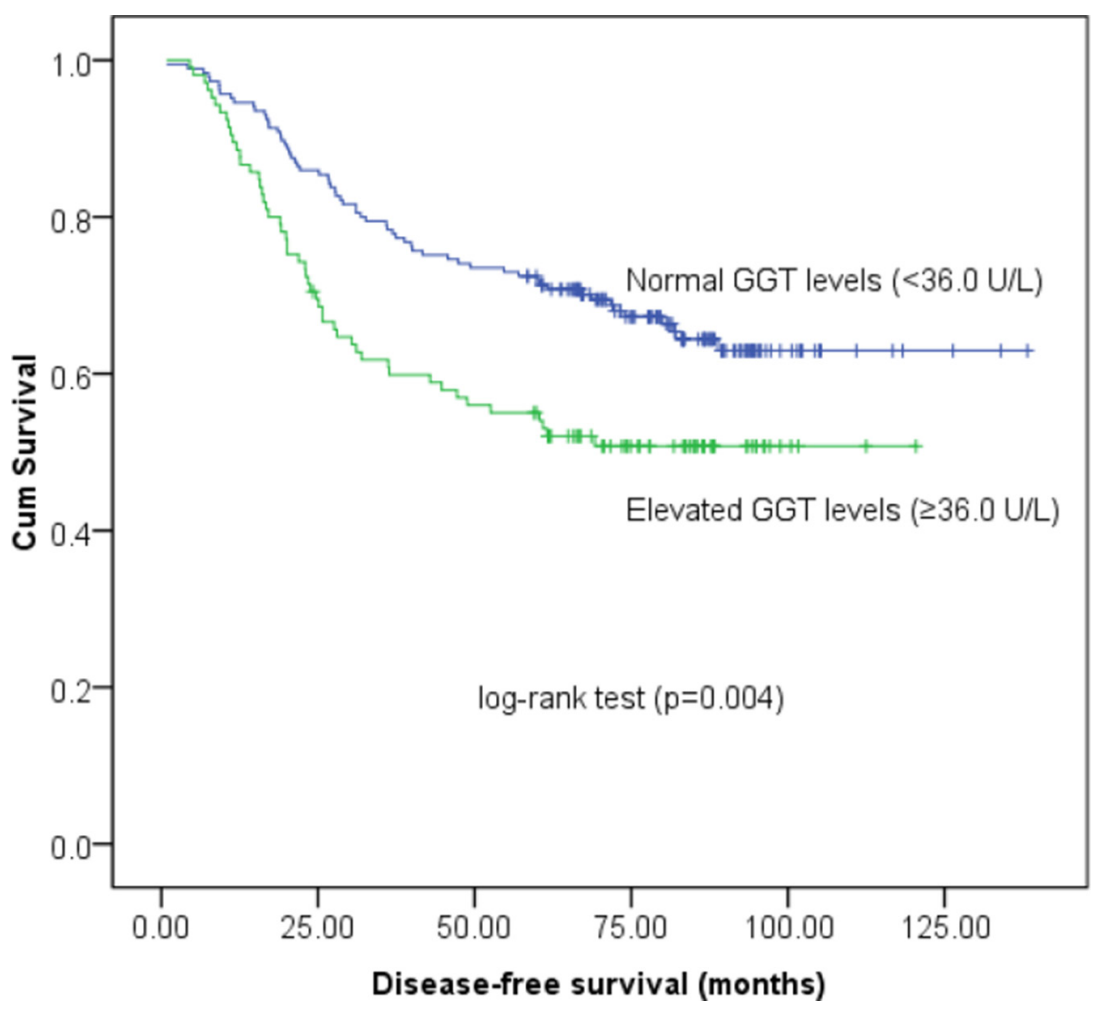

Figure 2: Kaplan-Meier survival estimates of disease-free survival (DFS) for 290 cervical cancer patients according to GGT groups. 
periaortic lymphadenectomy was utilized to treat those with early-stage disease. Locally advanced cases were concurrently treated with radiochemotherapy. Followup occurred for all patients every 3 months for the first 2 years after the initial treatment, every 6 months in the third year and yearly thereafter. A physical examination, ultrasonography and computed tomography were performed and tumor markers were evaluated during the follow-up period. Written informed consent was obtained. The study was approved by the independent ethics committee at the Anhui Provincial Hospital and was performed in accordance with the Declaration of Helsinki.

\section{Clinical and laboratory parameters}

Patients' baseline characteristics, including the clinical evaluations, laboratory test results, pathological conditions, treatments, and follow-up data were retrospectively reviewed and extracted from patient registries. All patients were managed according to the

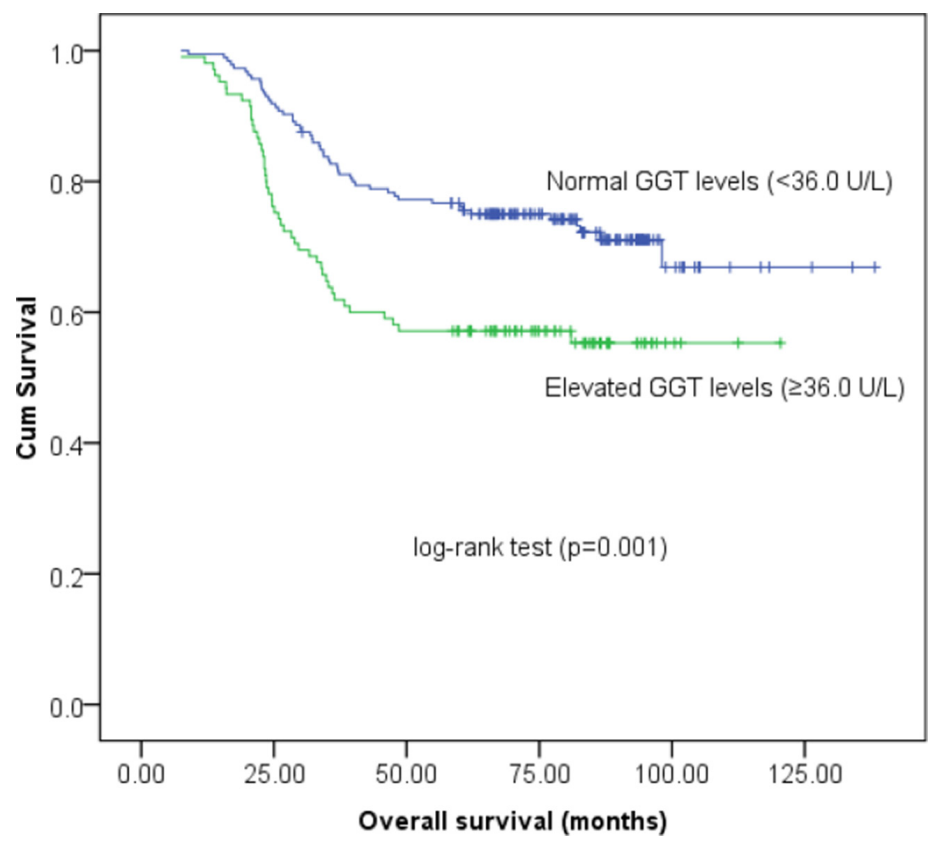

Figure 3: Kaplan-Meier survival estimates of overall survival (OS) for 290 cervical cancer patients according to GGT groups.

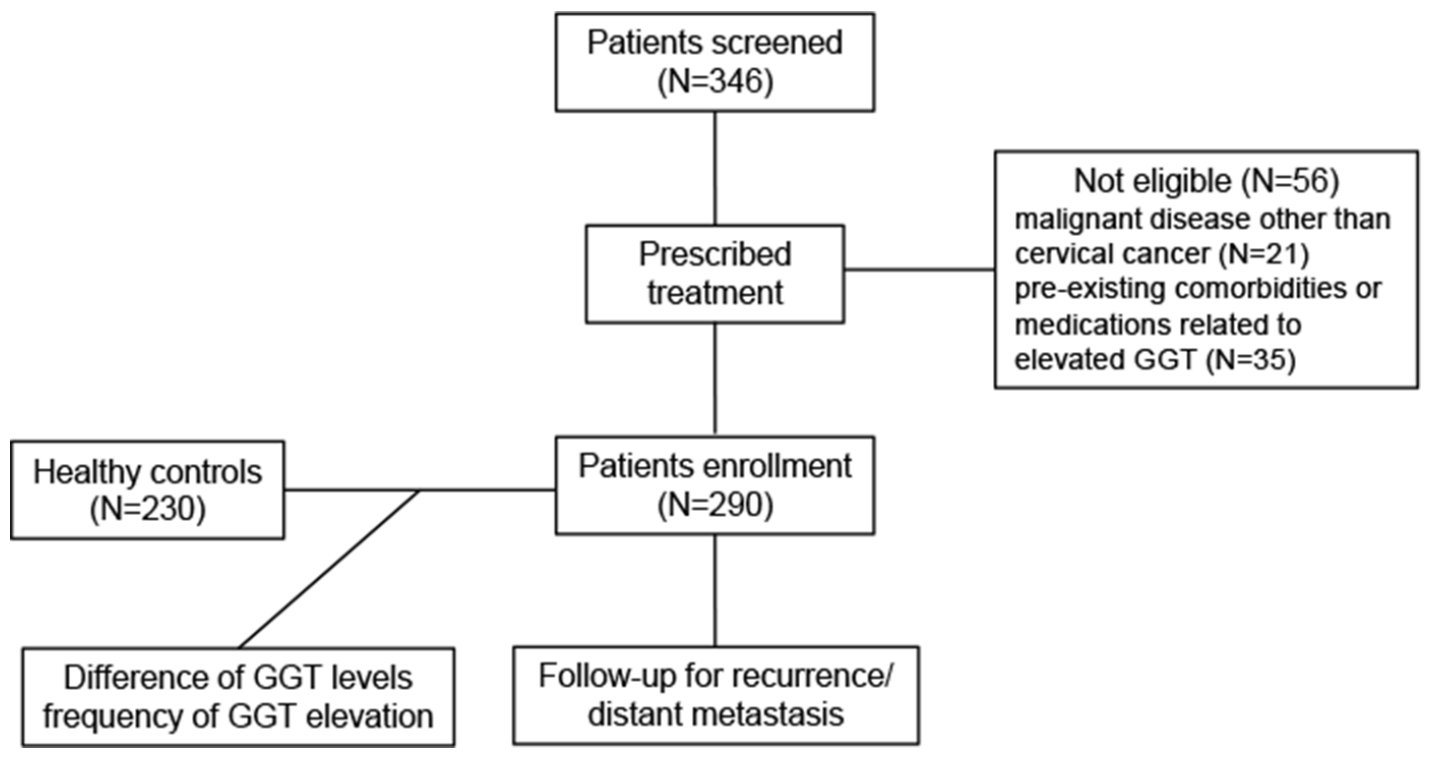

Figure 4: The flowchart of this study. GGT, gamma-glutamyltransferase. 
international guidelines. The International Federation of Gynecology and Obstetrics criteria (FIGO 2009) staging system was utilized to classify the tumor stage. The tumor size was defined according to the longest diameter measured using the post-operative pathological specimens. The degree of differentiation was categorized as poorly, moderately or well-differentiated. Serum GGT levels were determined with an enzyme kinetic assay using the optimal cutoff value of $36.0 \mathrm{U} / \mathrm{L}$, as previously described. In this manner, patients were divided into two risk groups: a high-risk GGT group $(\geq 36.0 \mathrm{U} / \mathrm{L})$ and a normal GGT group $(<36.0 \mathrm{U} / \mathrm{L})$. Disease-free survival (DFS) was calculated from the date of surgery to local recurrence/distant metastasis or to the last date of follow-up. Overall survival (OS) was defined as the time interval from the date of surgery to death from cervical cancer or to the last date of follow-up.

\section{Statistical analysis}

Age and GGT levels in the patient and control samples were compared using Student's $t$-test. Serum GGT concentration was analyzed as a categorical variable, after grouping with the threshold of $36.0 \mathrm{U} / \mathrm{L}$. The chi-square test or Fisher's exact test was applied to determine the different distribution of baseline and clinicopathologic parameters between groups. The Kaplan-Meier method was utilized to calculate survival curves, and survival differences were compared with the log-rank test. Cox proportional hazards models were used for univariate and multivariate analysis to determine hazard ratios (HRs) for the DFS- and OS-related variables. HRs with 95\% confidence intervals (CIs) and two-sided $P$ values were reported. All statistical analyses were performed with SPSS 23.0 (SPSS Inc., Chicago, IL, USA). A two-sided $P$ value of less than 0.05 was considered statistically significant.

\section{Author contributions}

Y.Z., and D.-B.W. conceived and designed the study. Y.Z. and J.W. wrote the manuscript. Z.S., G.C. and Y.Z. performed the statistical analysis. Y.-Y.S. and H.W. prepared the figures and tables. Y.Z., A.-J.Z. and D.-B.W. revised the manuscript. All authors reviewed the manuscript.

\section{CONFLICTS OF INTEREST}

The authors declared that they have no conflicts of interest.

\section{REFERENCES}

1. Ferlay J, Shin HR, Bray F, Forman D, Mathers C, Parkin DM. Estimates of worldwide burden of cancer in 2008: globocan 2008. Int J Cancer. 2010; 127:2893-2917.
2. Siegel RL, Miller KD, Jemal A. Cancer Statistics. CA Cancer J Clin. 2015; 65:5-29.

3. Schiffman M, Castle PE, Jeronimo J, Rodriguez AC, Wacholder S. Human papillomavirus and cervical cancer. Lancet. 2007; 370:890-907.

4. Solomon D, Breen N, McNeel T. Cervical cancer screening rates in the United States and the potential impact of implementation of screening guidelines. CA Cancer J Clin. 2007; 57:105-111.

5. Schiffman M, Solomon D. Clinical practice. Cervicalcancer screening with human papillomavirus and cytologic cotesting. N Engl J Med. 2013; 369:2324-2331.

6. Monk BJ, Tewari KS, Koh WJ. Multi-modality therapy for locally advanced cervical carcinoma: state of the art and future directions. J Clin Oncol. 2007; 25:2952-2965.

7. Tewari KS, Monk BJ. Recent achievements and future developments in advanced and recurrent cervical cancer: trials of the Gynecologic Oncology Group. Semin Oncol. 2009; 36:170-180.

8. Gadducci A, Tana R, Cosio S, Genazzani AR. The serum assay of tumour markers in the prognostic evaluation, treatment monitoring and follow-up of patients with cervical cancer: a review of the literature. Crit Rev Oncol Hematol. 2008; 66: 10-20.

9. Whitfield JB. Gamma glutamyl transferase. Crit Rev Clin Lab Sci. 2001; 38:263-355.

10. Pastore A, Federici G, Bertini E, Piemonte F. Analysis of glutathione: implication in redox and detoxification. Clin Chim Acta. 2003; 333:19-39.

11. Hanigan MH, Gallagher BC, Townsend DM, Gabarra V. Gamma-glutamyl transpeptidase accelerates tumor growth and increases the resistance of tumors to cisplatin in vivo. Carcinogenesis. 1999; 20:553-559.

12. Rollason JG, Pincherle G, Robinson D. Serum $\gamma$-glutamyltranspeptidase in relation to alcohol consumption. Clin Chim Acta. 1972; 39:75-80.

13. Pompella A, Corti A, Paolicchi A, Giommarelli C, Zunino F. $\gamma$-Glutamyltransferase, redox regulation and cancer drug resistance. Curr Opin Pharmacol. 2007; 7:360-366.

14. Pompella A, De Tata V, Paolicchi A, Zunino F. Expression of $\gamma$-glutamyltransferase in cancer cells and its significance in drug resistance. Biochem Pharmacol. 2006; 71:231-238.

15. Franzini M, Corti A, Lorenzini E, Paolicchi A, Pompella A, De Cesare M, Perego P, Gatti L, Leone R, Apostoli P, Zunino F. Modulation of cell growth and cisplatin sensitivity by membrane $\gamma$-glutamyltransferase in melanoma cells. Eur J Cancer. 2006; 42:2623-2630.

16. Dominici S, Valentini M, Maellaro E, Del Bello B, Paolicchi A, Lorenzini E, Tongiani R, Comporti M, Pompella A. Redox modulation of cell surface protein thiols in U937 lymphoma cells: the role of $\gamma$-glutamyl transpeptidasedependent $\mathrm{H} 2 \mathrm{O} 2$ production and S-thiolation. Free Radic Biol Med. 1999; 27:623-635.

17. Hofbauer SL, Stangl KI, Martino M, Lucca I, Haitel A, Shariat SF, Klatte T. Pretherapeutic gamma- 
glutamyltransferase is an independent prognostic factor for patients with renal cell carcinoma. Br J Cancer. 2014; 111:1526-1531.

18. Seebacher V, Polterauer S, Grimm C, Rahhal J, Hofstetter G, Bauer EM, Husslein H, Leipold H, Marth C, Reinthaller A, Concin N. Prognostic significance of gammaglutamyltransferase in patients with endometrial cancer: a multi-centre trial. Br J Cancer. 2012; 106:1551-1555.

19. Yang F, Zhang S, Yang H, Luo K, Wen J, Hu Y, Hu R, Huang Q, Chen J, Fu J. Prognostic significance of gammaglutamyltransferase in patients with resectable esophageal squamous cell carcinoma. Dis Esophagus. 2015; 28: 496-504.

20. Polterauer S, Hofstetter G, Grimm C, Rahhal J, MailathPokorny M, Kohl M, Concin N, Tempfer C, Marth C, Reinthaller A. Relevance of gamma-glutamyltransferase-a marker for apoptotic balance - in predicting tumor stage and prognosis in cervical cancer. Gynecol Oncol. 2011; 122:590-594.
21. Strasak AM, Goebel G, Concin H, Pfeiffer RM, Brant LJ, Nagel G, Oberaigner W, Concin N, Diem G, Ruttmann E, Gruber-Moesenbacher U, Offner F, Pompella A, et al. Prospective study of the association of serum gammaglutamyltransferase with cervical intraepithelial neoplasia III and invasive cervical cancer. Cancer Res. 2010; 70:3586-3593.

22. Dalpiaz O, Pichler M, Mrsic E, Reitz D, Krieger D, Venturino L, Bezan A, Stojakovic T, Pummer K, Zigeuner R, Hutterer GC. Preoperative serum gammaglutamyltransferase (GGT) does not represent an independent prognostic factor in a European cohort of patients with non-metastatic renal cell carcinoma. J Clin Pathol. 2015; 68:547-551.

23. Lee DH, Jacobs DR. Association between serum concentrations of persistent organic pollutants and $\gamma$-glutamyltransferase: results from the National Health and Examination Survey 1999-2002. Clin Chem. 2006; 52: $1825-1827$. 